\title{
Exploratory structural equation modeling of the general decision-making style inventory
}

\section{Modelo de ecuaciones estructurales exploratorio del} general decision-making style inventory

\author{
Cecilia Reyna ${ }^{\mathrm{a}, \mathrm{b}}$, María Victoria Ortiz ${ }^{\mathrm{a}}$ y Romina Graciela Revilla ${ }^{\mathrm{a}}$ \\ ${ }^{a}$ Universidad Nacional de Córdoba, Córdoba, Argentina \\ ${ }^{b}$ Consejo Nacional de Investigaciones Científicas y Técnicas (Conicet), Argentina
}

\begin{abstract}
The General Decision-Making Style Inventory has been validated with samples from several countries, but there are no reports about its validity in Latin American countries. In this study we assessed the underlying structure of the GDMSI in a sample from Argentina and compared a confirmatory factor analysis (CFA) model with a more flexible model that combines exploratory and confirmatory parts, the exploratory structural equation modeling (ESEM) approach. In general, the results support the construct validity of the GDMSI and confirm the potential and superiority of the ESEM procedures to assess the relationship between the items and the underlying dimensions, compared to more restrictive models.
\end{abstract}

Keywords: decision-making styles, internal structure, confirmatory factor analysis, exploratory structural equation modeling.

\section{Resumen}

El General Decision-Making Style Inventory ha sido validado con muestras de varios países, sin reportes sobre su validez en países latinoamericanos. En este estudio evaluamos la estructura subyacente al GDMSI en una muestra de habitantes de Argentina y comparamos un modelo clásico de análisis factorial confirmatorio (CFA) con un modelo más flexible que combina modelos exploratorios y confirmatorios, el modelo de ecuaciones estructurales exploratorio (ESEM). En general, los resultados muestran la validez de constructo del GDMSI y confirman la potencialidad y superioridad de los procedimientos ESEM para evaluar las relaciones entre los ítems y las dimensiones subyacentes, comparado con modelos más restrictivos.

Palabras clave: estilos de toma de decisiones, estructura interna, análisis factorial confirmatorio, modelo de ecuaciones estructurales exploratorio.

Contacto: C. Reyna. Laboratorio de Psicología Cognitiva, Facultad de Psicología, Universidad Nacional de Córdoba, Ciudad Universitaria, (5000) Córdoba, Argentina. creyna@psyche.unc.edu.ar

Cómo citar este artículo:

Reyna, C., Ortiz, M. V. y Revilla, R. G. (2014). Exploratory Structural Equation Modeling of the General Decision-Making Style Inventory. Revista de Psicología, 23(1), 33-39. doi: 10.5354/0719-0581.2014.32872 


\section{Introduction}

The decision-making process involves the assessment of existing information in order to choose the most adequate solution among available alternatives in a given situation (Gambetti, Fabbri, Bensi, \& Tonetti, 2008). Decisions are affected by three factors: decision, context, and individual differences. The latter is the least studied (Appelt, Milch, Handgraaf, \& Weber, 2011); therefore, researchers have highlighted the need to promote the evaluation of personal characteristics, which allow a better understanding of the decision-making process (Loo, 2000).

Decision-making styles differ from personality traits, the latter having a more stable nature. In contrast, a decisionmaking style is "the learned, habitual response pattern exhibited by an individual when confronted with a decision situation" (Scott \& Bruce, 1995, p. 820); thus, the decisionmaking process is based on the habit of reacting in a specific way according to particular context because it may affect the most prevailing decision style.

Based on previous theoretical and empirical studies, Scott and Bruce (1995) proposed four decision-making styles: 1) rational: characterized by the exhaustive exploration and logical evaluation of alternatives; 2) intuitive: based on faith, intuitions, and sensations; 3) dependent: characterized by the quest for advice and guidelines from others; and 4) avoidant: characterized by postponing the decision-making process. The authors developed a self-administered instrument designed to measure the four theoretical decision-making styles, referred to as the General Decision-Making Style Inventory (GDMSI); however, this yielded an additional style, termed 'spontaneous' (5), characterized by a sense of immediacy and the desire to make a decision as quickly as possible. The underlying structure of the GDMSI involves a five-factor structure, which was replicated with samples from university students, engineers, and technicians.

The psychometric properties of the GDMSI have been studied in different countries (e.g., Canada, the Netherlands, Italy, and the UK). In terms of construct validity, exploratory factor analyses (EFA) support the theoretical five-factor structure (Baiocco, Laghi, \& D’Alessio, 2009; Curseu \& Schruijer, 2012; Gambetti et al., 2008; Loo, 2000; Spicer \& Sadler-Smith, 2005). Principal component analysis and EFA with the principal axis extraction method have been used to explore the underlying structure, either with Oblimin or Varimax rotations. There is evidence that some items yield small factor loadings and/or that several positive crossloadings are found for some items in the spontaneous and intuitive dimensions or avoidant and dependent dimensions (Curseu \& Schruijer, 2012; Gambetti et al., 2008; Spicer \& Sadler-Smith, 2005). Furthermore, the studies that employed confirmatory factor analysis (CFA) using the maximum likelihood (ML) estimation state that the five-factor model is a better fit, compared to models with two, three, or four factors (Baiocco et al., 2009; Gambetti et al., 2008; Spicer \& Sadler-Smith, 2005), and the five-factor model with correlated factors has shown better model-data fit than models with uncorrelated factors (Curseu \& Schruijer, 2012; Loo, 2000).

Thus, previous studies relied on EFA and/or CFA to examine the underlying dimensions of the GDMSI. In CFA models, which are based on theory or previous studies, factor loadings are restricted to zero, therefore simple measurement structures are achieved. However, the restriction of CFA models generally cannot reveal the nature of the relationships between items. Thus, extensive modifications of models are often performed to find a structure that provides a proper fit (Asparouhov \& Muthén, 2009).

As an alternative to these procedures, a less restrictive analytical strategy has been proposed: the exploratory structural equation modeling (ESEM) approach which combines an EFA with factor rotation in the framework of structural equation modeling (SEM). The ESEM provides information about all the parameters usually reported in SEM allowing for factor rotation and correlation of residuals. The main advantage of the ESEM is that it easily integrates EFA and SEM models, avoiding the sequential steps of EFA-CFA (Asparouhov \& Muthén, 2009). This analytical strategy has been shown to be superior to CFA models based on both simulation and empirical studies (c.f., Marsh et al., 2009; Marsh et al., 2010), and has the potential to model complex structures, such as the longitudinal or multi-group EFA (e.g., Grimm, Steele, Ram, \& Nesselroade, 2013).

An enhanced measurement of decision-making styles will contribute to a better understanding of the decision process in different contexts (e.g., in education, work, health, etc.) and may allow for the analysis of the relationship among the decision-making styles and other constructs. In this regard, it has been observed that avoidant and dependent styles are positively correlated with the self-reported ratings of stress (e.g., Allwood \& Salo, 2012; Salo \& Allwood, 2011); and that rational and avoidant styles are positively correlated with anxiety and depression (Schoemaker, 2010).

Therefore, in consideration of the need for instruments to measure the decision-making styles as adapted to local contexts, in this study we aim at examining the underlying structure of the GDMSI. In the first step, we fit a model according 
to the theoretical structure observed in previous studies that conducted a CFA, which involves restricting cross-loadings to zero, and subsequently we fit a flexible model (ESEM) to the structure and compared the solutions.

\section{Method}

\section{Participants}

A convenience sample was employed, which comprised 717 subjects ( $60.4 \%$ women, $39.6 \%$ men) from 18 to 65 years of age $(M=27.54, S D=9.38)$. Subjects received oral and written information about the aims of the study. Participation was voluntary; the data was handled under conditions of confidentiality and anonymity, and the participants were told that results would only be used for research purposes.

\section{Instruments}

The Galotti et al. (2006) version of the General DecisionMaking Styles Inventory developed by Scott and Bruce (1995) was analyzed. The original version by Scott and Bruce comprises 25 items, and the reliability indices (Cronbach's alpha) they reported were: rational style $=$ .77 to .85 , intuitive style $=.78$ to .84 , avoidance style $=$ .93 to .94 , dependent style $=.68$ to .86 , and spontaneous style $=.87$. Galotti et al. (2006) added one item to each dimension (see Table 2) in their version in order to improve the reliability of the scales, and they found the following Cronbach's alpha indices: rational style $=.77$; intuitive style $=.82$; avoidance style $=.87$; dependent style $=.81$; and spontaneous style $=.87$. Items response format was a 7 -point Likert scale $(1=$ strongly disagree, $7=$ strongly agree) and they are grouped into five dimensions: rational, intuitive, dependent, avoidant, and spontaneous.

As mentioned earlier, the five-factor structure has been replicated in several studies, and internal consistency indices range from .67 to .90 for the dimensions (e.g., Baiocco et al., 2009; Curseu \& Schruijer, 2012; Gambetti et al., 2008; Spicer \& Sadler-Smith, 2005).

In this research, the English version of the inventory was tested in a preliminary study taking into account the guidelines collected by Muñiz, Elosua, and Hambleton (2013) involving the following steps: 1) translation from English to Spanish by two specialists in the English language and comparison of the differences, carried out jointly with specialists in psychological assessment; 2) a pilot study with 15 adults to assess cultural appropriateness, semantic clarity, and grammatical aspects of the items and instruc- tions; and 3) discussion within the research group on the results of the pilot study.

\section{Procedure}

Data collection was developed at certain universities and public places. Questionnaires were individually completed. Data analyses were conducted with MPlus 7.11 (Muthén \& Muthén, 1998-2012) as follows:

- Descriptive analyses of cases (subjects) and variables were performed. Cases with $Z> \pm 3.29$ were considered univariate outliers; and multivariate outliers were at $p$ $<.001$ (Tabachnick \& Fidell, 2007). Values of skewness and kurtosis in the range \pm 1 were considered excellent, and in the range \pm 1.5 , they were considered acceptable (George \& Mallery, 2001).

- A CFA with ML estimation was conducted.

- The ESEM analysis with an ML estimation method was conducted. Because several methods of rotation are available (e.g., varimax, quartimin, geomin, target) and the choice of one or another is a question under current research, we decided to use the geomin rotation method (cf., Marsh et al., 2009).

For CFA and ESEM analyses, several indicators were used to assess model-data fit (Byrne, 2010; Kline, 2011): $\chi^{2} ; \chi^{2} /$ gl, with values below three were considered indicative of a good fit; standardized root mean square residual (SRMR) equal to or lower than .05 indicated a very good fit and values lower than or equal to .08 were considered acceptable. Tucker-Lewis index (TLI) and comparative fit index (CFI) values below .90 indicate poor fit and values higher than .95 indicate a good fit. Root mean square error of approximation (RMSEA), values lower than 05 indicate a good fit, and between .05 and .08 indicate an acceptable fit. Additionally, the Akaike Information Criterion (AIC) and the Bayesian Information Criterion (BIC) were considered; lower values in those indices reflect a better model-data fit. Finally, standardized factor loadings were interpreted.

\section{Results}

Preliminary analysis showed that no variable had more than $5 \%$ of missing data, so it was decided no imputation method was needed. A total of 22 cases were found to be univariate outliers, and none were found to be a multivariate outlier. Regarding skewness (S) and kurtosis (K), excellent or acceptable values were observed. Only three items showed values of kurtosis around 2 (i.e., V6 S = 
-1.32, $\mathrm{K}=1.97$; V21 $\mathrm{S}=-1.26, \mathrm{~K}=2.07 ; \mathrm{V} 25 \mathrm{~S}=-1.17$, $\mathrm{K}=2.03)$. This was taken into account in the following analysis.
As shown in Table 1, the model-data fit for the CFA was acceptable for some indices (e.g., RMSEA) and unacceptable for some others (e.g., CFI and TLI).

Table 1

Adjustment Indices of CFA and ESEM Models

\begin{tabular}{cccccccccc}
\hline & $\chi^{2}$ & $\mathrm{df}$ & $\chi^{2} / \mathrm{df}$ & SRMR & CFI & TLI & $\begin{array}{c}\text { RMSEA } \\
(90 \% \text { CI })\end{array}$ & AIC & BIC \\
\hline CFA & 1683.5 & 395 & 4.26 & .083 & .80 & .78 & $.067(.064-.071)$ & 74446.7 & 74904.2 \\
ESEM & 811.1 & 295 & 2.75 & .030 & .92 & .88 & $.049(.045-.053)$ & 73774.2 & 74689.2 \\
\hline
\end{tabular}

Note: SRMR = Standardized Root Mean Square Residual; CFI = Comparative Fit Index; TLI = Tucker-Lewis Index; RMSEA = Root Mean Square Error of Approximation; CI = confidence interval; AIC = Akaike Information Criterion; BIC = Bayesian Information Criterion.

Regarding the ESEM, most indices suggest a good modeldata fit (e.g., RMSEA and CFI) although TLI does not reach the suggested value for an acceptable model. According to the information criteria, the ESEM model provides a better fit than the CFA model although it should be noted that factor structure in this case is more complex. For the CFA, eight out of the ten correlations among factors were statistically significant, with absolute values from .20 to .46 , and a similar patter was found for the ESEM model (Table 2).

Table 2

Correlation Between Factors: CFA and ESEM models

\begin{tabular}{|c|c|c|c|c|c|c|c|c|c|c|}
\hline & \multicolumn{5}{|c|}{ CFA } & \multicolumn{5}{|c|}{ ESEM } \\
\hline & $\mathrm{F} 1$ & F2 & F3 & $\mathrm{F} 4$ & F5 & $\mathrm{F} 1$ & F2 & F3 & $\mathrm{F} 4$ & F5 \\
\hline $\mathrm{F} 1$ & 1 & & & & & 1 & & & & \\
\hline $\mathrm{F} 2$ & .384 & 1 & & & & .239 & 1 & & & \\
\hline F3 & .045 & .186 & 1 & & & .015 & .124 & 1 & & \\
\hline F4 &.$\underline{148}$ & .459 & .342 & 1 & & .081 & .328 & .329 & 1 & \\
\hline F5 & .022 & -.463 & .130 & -.203 & 1 & .101 & -.305 & .124 & -.157 & 1 \\
\hline
\end{tabular}

Note: $\mathrm{CFA}=$ Confirmatory Factor Analysis; ESEM = Exploratory Structural Equation Modeling; F1 = Intuitive; F2 = Spontaneous; F3 = Dependent; F4 = Avoidance; F5 $=$ Rational. Bold $=p<.001$. Underlined $=p<.01$. Italics $=p<.05$.

All items yielded significant factor loadings on the theoretical dimensions, but some items also loaded onto other dimensions (Table 3). Regarding the rational, avoidant, dependent, and spontaneous styles, although significant loadings were observed in other dimensions, the largest factor loading was observed in the hypothesized theoretical style. Three items of the intuitive style exhibited higher loadings in other dimensions. Item number six (Generalmente tomo decisiones que me parecen adecuadas/"I generally make decisions that seem right to me") and number 29 (Al tomar una decisión, elijo la opción que considero mejor para mí/“When I make a decision, I tend to go with the choice that considers the best to me") exhibited higher loadings in the rational style. Item number 13 (Para resolver si una decisión es adecuada, para mí es más importante lo que siento que lo que pienso/"When I make a decision, it is more important for me to feel the decision is right than to have a rational reason for it") yielded loadings of similar magnitude on the intuitive and spontaneous styles. 
Table 3

Factor Solution of the CFA and the ESEM of the GDMSI

\begin{tabular}{|c|c|c|c|c|c|c|c|c|c|c|}
\hline \multirow[b]{2}{*}{ Items } & \multicolumn{5}{|c|}{ CFA } & \multicolumn{5}{|c|}{ ESEM } \\
\hline & $\mathrm{F} 1$ & $\mathrm{~F} 2$ & F3 & F4 & F5 & $\mathrm{F} 1$ & $\mathrm{~F} 2$ & F3 & $\mathrm{F} 4$ & F5 \\
\hline V1 & & & & & .417 & .156 & -.177 & -.012 & -.043 & .319 \\
\hline $\mathrm{V} 2$ & .753 & & & & & .809 & -.01 & -.003 & -.04 & -.015 \\
\hline V3 & & & & .456 & & $\underline{.106}$ & -.088 & .084 & .476 & .066 \\
\hline V4 & & & .686 & & & .034 & -.037 & .677 & .048 & -.071 \\
\hline V5 & .786 & & & & & .802 & .031 & -.031 & 0 & .025 \\
\hline V6 & .239 & & & & & .249 & -.032 & -.074 & -.078 & .382 \\
\hline V7 & & .705 & & & & -.048 & .644 & .107 & .062 & -.054 \\
\hline V8 & & & .571 & & & -.069 & .074 & .565 & -.04 & .03 \\
\hline V9 & & .602 & & & & .01 & .537 & .05 & .052 & -.082 \\
\hline V10 & & & & & .527 & .016 & -.286 & .044 & .18 & .401 \\
\hline V11 & & .55 & & & & .002 & .663 & -.163 & -.116 & .055 \\
\hline V12 & & & .599 & & & .054 & .05 & .575 & .003 & .055 \\
\hline V13 & .484 & & & & & .324 & .333 & .108 & .061 & -.06 \\
\hline V14 & & & .687 & & & .009 & 0 & .719 & -.091 & .106 \\
\hline V15 & & .768 & & & & .008 & .764 & .079 & .001 & .008 \\
\hline V16 & & & & & .65 & -.019 & -.35 & .058 & .056 & .46 \\
\hline V17 & & & .704 & & & -.044 & -.034 & .713 & .005 & .03 \\
\hline V18 & & & & .701 & & -.005 & .072 & .017 & .676 & .05 \\
\hline V19 & & .643 & & & & .138 & .51 & -.006 & .201 & -.036 \\
\hline V20 & & & & .75 & & .019 & -.006 & -.027 & .777 & .028 \\
\hline V21 & & & & & .659 & -.077 & .012 & -.006 & .025 & .728 \\
\hline V22 & & & & .676 & & -.009 & .227 & -.063 & .604 & .008 \\
\hline V23 & & & & .736 & & -.03 & -.013 & .016 & .722 & $\underline{-.093}$ \\
\hline V24 & .59 & & & & & .429 & .315 & .045 & .084 & .008 \\
\hline V25 & & & & & .621 & -.027 & .081 & .036 & .006 & .708 \\
\hline $\mathrm{V} 26^{*}$ & & & .52 & & & .007 & .017 & .483 & .209 & -.232 \\
\hline $\mathrm{V} 27^{\star}$ & & .405 & & & & .047 & .435 & -.106 & .005 & .049 \\
\hline $\mathrm{V} 28^{\star}$ & & & & & .705 & .021 & -.084 & -.001 & -.042 & .66 \\
\hline V29* & .253 & & & & & .136 & .188 & -.008 & .001 & .352 \\
\hline V30* & & & & .522 & & -.036 & .048 & .013 & .487 & -.107 \\
\hline
\end{tabular}

Note: $C F A=$ Confirmatory Factor Analysis, ESEM = Exploratory Structural Equation Modeling F1 = Intuitive; F2 = Spontaneous; F3 = Dependent; F4 = Avoidance; F5 = Rational. ${ }^{*}=$ items added by Galotti et al. $(2006)$. Bold $=p<.001$. Underlined $=p<.01$. Italics $=p<.05$. 


\section{Discussion}

This research aimed to examine the psychometric properties of the General Decision-Making Styles Inventory initially proposed by Scott and Bruce (1995) and adapted by Galotti et al. (2006) in the Argentinean population. We assessed these properties by a CFA and with an ESEM (Asparouhov \& Muthén, 2009).

The results showed that the ESEM model had a better fit compared to the CFA structure. For the CFA model, comparative fit indices showed an improper fit of the data to the model, and according to the information criteria, the ESEM model showed a better fit.

The ESEM model revealed that some items yielded significant factor loadings on dimensions different from those proposed in the original scale. Comparison of the English and Spanish versions of those items revealed that it is likely that the discrepancies that were found may be due to translation problems. Specifically, in English, for items 6 and 29 the word "feel" is used, whereas in Spanish we use the verb parecer (seem) or considerar (consider) which may have a different interpretation. Item 13, which yielded factor loadings of similar size in the intuitive and spontaneous dimensions, is an example that shows the relationships of an item with various dimensions or styles and the relationships among dimensions.

The use of ESEM in this research revealed certain kinds of relationships among latent factors and items that are unnoticed in other type of analyses. It allowed a better approach to the nature of the underlying relationships to the items of the scale, without applying restrictions and later correlations between errors of the indicators. This is consistent with the observation that these styles are not mutually exclusive (Scott \& Bruce, 1995). Future studies should consider the evidence provided here when assessing the relationship among the decision-making styles and other constructs or variables.
Despite these promising results, further psychometric studies are still needed. For instance, it would be appropriate to assess whether rephrasing the items with translation problems produces meaningful changes in the underlying structure of the test. In addition, further evidence on convergent validity is needed for the GDMSI styles. For example, in relation to the dimensions of Rational-Experiential Inventory (Pacini \& Epstein, 1999) or with the Cognitive Reflection Test (CRT, Frederick, 2005), which have been associated with the type of processing of System 1 (fast, automatic, without requiring cognitive effort) and System 2 (deliberative, partly conscious, and slow, requiring cognitive resources) (cf., Evans \& Stanovich, 2013; Kahneman \& Frederick, 2002). Similarly, it would be advisable to gather evidence of criterion validity taking into consideration observational evidence from everyday life.

In addition, some limitations of the study should be mentioned. The sample was a convenience sample, which imposes limitations on generalizing these results for the broader population. Furthermore, it would be convenient to adapt the GDMSI to specific contexts, such as clinical, legal, military, economic, and political contexts, which have been shown to have specific relations among different decision-making styles and constructs such as stress or anxiety (e.g., Allwood \& Salo, 2012; Thunholm, 2008) in order to obtain evidence of the predominant styles in such contexts. Also, further research can identify the relationships among the decision-making styles and affective states or specific emotions (Reyna et al., 2013) and contribute to understanding the role of emotions in the decision-making process.

To sum up, having instruments to assess styles of decisionmaking in the local context will allow the consideration of their role in relation to other processes and their relationship to other variables, which will allow for comparisons among or between studies in other regions.

In general, the results of this study of an Argentinean sample show structural similarities to those reported in the original studies in the US samples (Scott \& Bruce, 1995) and subsequent validation studies in samples from other countries.

\section{References}

Allwood, C. M. \& Salo, I. (2012). Decision-making styles and stress. International Journal of Stress Management, 19(1), 3447. doi:1.1037/a0027420

Appelt, K. C., Milch, K. F., Handgraaf, M. J. J., \& Weber, E. U. (2011). The Decision Making Individual Differences Inventory and guidelines for the study of individual differences in judgment and decisionmaking research. Judgment and Decision Making, 6(3), 252-262.

Asparouhov, T. \& Muthén, B. (2009). Exploratory structural equation modeling. Structural Equation Modeling, 16, 397-438. doi:1.1080/10705510903008204

Baiocco, R, Laghi, F., \& D’Alessio, M. (2009). Decision-making style among adolescents: Relationship sensation seeking and locus of control. Journal of Adolescence, 32, 963-976. doi:1.1016/j. adolescence.2008.08.003

Byrne, B. M. (2010). Structural equation modeling with AMOS (2nd ed.). New York: Routledge. 
Curseu, P. L. \& Schruijer, S. G. L. (2012). Decision styles and rationality: An analysis of the predictive validity of the general decision-making style inventory. Educational and Psychological Measurement, 72(6), 1053-1062. doi:1.1177/0013164412448066

Evans, J. St. B. T. \& Stanovich, K. E. (2013). Dual-Process theories of higher cognition: Advancing the debate. Perspectives on Psychological Science, 8(3), 223-241. doi:1.1177/1745691612460685

Frederick, S. (2005). Cognitive reflection and decision making. The Journal of Economic Perspectives, 19, 25-42. doi:1.1257/089533005775196732

Galotti, K. M., Ciner, E., Altenbaumer, H. E., Geerts, H. J., Rupp, A., \& Woulfe, J. (2006). Decision-making styles in a real-life decision: Choosing a college major. Personality and Individual Differences, 41(4), 629-639. doi:1.1016/j. paid.2006.03.003

Gambetti, E., Fabbri, M., Bensi, L., \& Tonetti, L. (2008). A contribution to the Italian validation of the general decisionmaking style inventory. Personality and Individual Differences, 44(4), 842-852. doi:1.1016/j.paid.2007.1.017

George, D. \& Mallery, M. P. (2001). SPSS for Windows step by step: A simple guide and reference. Boston, MA: Allyn \& Bacon.

Grimm, K. J., Steele, J. S., Ram, N., \& Nesselroade, J. R. (2013). Exploratory forms of latent growth modeling in structural equation modeling. Structural Equation Modeling, 20(4), 568591. doi:1.1080/10705511.2013.824775

Kahneman, D. \& Frederick, S. (2002). Representativeness revisited: Attribute substitution in intuitive judgment. In T. Gilovich, D. Griffin, \& D. Kahneman (Eds.), Heuristics and biases: The psychology of intuitive judgment (pp. 49-81). New York, NY: Cambridge University Press.

Kline, R. B. (2011). Principles and practice of structural equation modeling (3rd ed.). New York: The Guilford Press.

Loo, R. (2000). A psychometric evaluation of the General Decision-Making Style Inventory. Personality and Individual Differences, 29(5), 895-905. doi:10.1016/S01918869(99)00241-X

Marsh, H. W., Lüdtke, O., Muthén, B., Asparouhov, T., Morin, A. J. S., Trautwein, U., \& Nagengast, B. (2010). A new look at the big-five factor structure through exploratory structural equation modeling. Psychological Assessment, 22, 471-491. doi:1.1037/a0019227
Marsh, H. W., Muthén, B., Asparouhov, T., Lüdtke, O., Robitzsch, A., Morin, A. J. S., \& Trautwein, U. (2009). Exploratory structural equation modeling, integrating CFA and EFA: Applications to students' evaluations of university teaching. Structural Equation Modeling, 16(3), 439-476. doi:1.1080/10705510903008220

Muñiz, J., Elosua, P., \& Hambleton, R. K. (2013). Directrices para la traducción y adaptación de los test: segunda edición. Psicothema, 25(2), 151-157. doi:1.7334/ psicothema2013.24

Muthén, L. K. \& Muthén, B. O. (1998-2012). Mplus User's Guide (7th ed.). Los Angeles, CA: Author.

Pacini, R. \& Epstein, S. (1999). The relation of rational and experiential information processing styles to personality, basic beliefs, and the ratio-bias phenomenon. Personality Processes and Individual Differences, 76(6), 972-987. doi:1.1037/00223514.76.6.972

Reyna, C. E., Brussino, S. A., Mola, D., Belaus, A., Francovich, M., \& Acosta, C. (2013, july). Decision-making styles and emotions. In J. C. Alchieri \& J. Barreiros Porto (Orgs.), Anais do XXXIV Congresso Interamericano de Psicologia (p. 1503). Brasilia, Brazil: SBPOT.

Salo, I. \& Allwood, C. M. (2011). Decision-making styles, stress and gender among investigators. Policing: An International Journal of Police Strategies \& Management, 34(1), 97-119. doi:1.1108/13639511111106632

Schoemaker, A. F. (2010). The relationship between decision-making style and negative affect in college students (Unpublished master's thesis). Drexel University, Philadelphia, United States.

Scott, S. G. \& Bruce, R. A. (1995). Decision-making style: The development and assessment of a new measure. Educational \& Psychological Measurement, 55, 818-831. doi:1.1177/0013164495055005017

Spicer, D. P. \& Sadler-Smith, E. (2005). An examination of the general decision making style questionnaire in two UK samples. Journal of Managerial Psychology, 20(2), 137-149. doi:1.1108/02683940510579777

Tabachnick, B. G. \& Fidell, L. S. (2007). Using multivariate statistics (5th ed.). New York: Harper \& Row.

Thunholm, P. (2008). Decision-making styles and physiological correlates of negative stress: Is there a relation? Scandinavian Journal of Psychology, 49(3), 213-219. doi:1.1111/j.1467945.2008.0064.x 